\title{
Weathering of granite and biotite in
} ice

\author{
YOUNGSOOK HUH ${ }^{1 *}$ AND SEUNGSOO LEE ${ }^{1}$
}

${ }^{1}$ School of Earth and Environmental Sciences, Seoul National University, Seoul 08826, Korea

In the presence of ice there is differential weathering of minerals [1] and freeze-concentration of solute in grain boundaries, enhancing reaction rates $[2,3]$. We simulated frost weathering in the lab to examine chemical weathering of minerals in the absence of the physical action of glacial abrasion. Parallel batch dissolution experiments were carried out, one at $-20^{\circ} \mathrm{C}$ and another at room temperature, using powdered granite and biotite. Dissolved major cation concentrations and lithium isotope ratios were measured.

In granite dissolution experiments, XRD analysis of the residual solid suggested weathering of feldspars and micas. However, ice and aqueous phases did not differ significantly in their major element compositions. In biotite dissolution experiments, there were significant changes suggesting dissolution of sulfides and/or precipitation of Si-containing phases. The Si-Na-K ratios indicated that in ice, biotite weathered to vermiculite, whereas in the aqueous phase weathering proceeded to kaolinite.

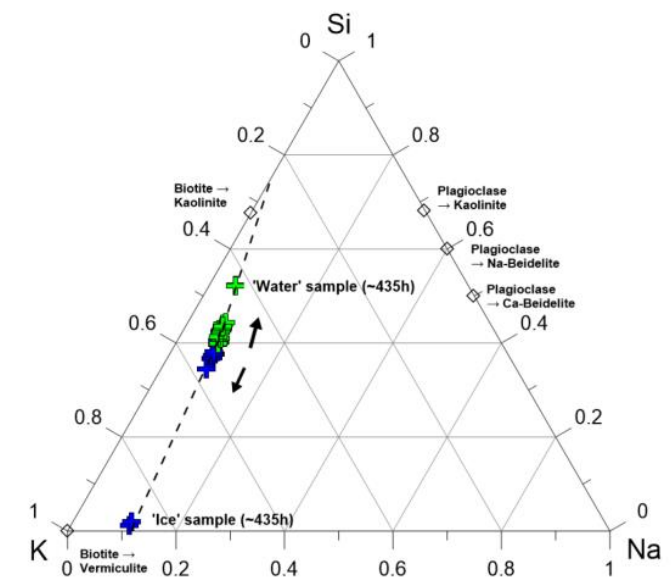

Figure 1: Ternary diagram using the dissolved $\mathrm{Na}, \mathrm{K}$, and Si concentrations following [4].

[1] Torres et al. (2017) PNAS 114, 8716-8721. [2] Kim et al. (2010) ES\&T 44, 4142-4148. [3] Kim et al. (2015) ES\&T 49, 10937-10944. [4] Jacobson et al. (2003) GCA 67, 29-46. 